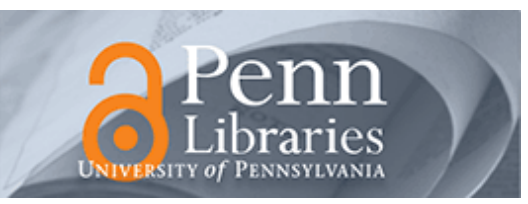

University of Pennsylvania

ScholarlyCommons

$12-9-2011$

\title{
Schwann Cell Proliferation and Macrophage Infiltration Are Evident at Day 14 after Painful Cervical Nerve Root Compression in the Rat
}

Yu-Wen Chang

University of Pennsylvania

Beth A. Winkelstein

University of Pennsylvania, winkelst@seas.upenn.edu

Follow this and additional works at: https://repository.upenn.edu/be_papers

Part of the Biomedical Engineering and Bioengineering Commons

\section{Recommended Citation}

Chang, Y., \& Winkelstein, B. A. (2011). Schwann Cell Proliferation and Macrophage Infiltration Are Evident at Day 14 after Painful Cervical Nerve Root Compression in the Rat. Retrieved from https://repository.upenn.edu/be_papers/188

Chang, Y. \& Winkelstein, B. A. (2011). Schwann Cell Proliferation and Macrophage Infiltration Are Evident at Day 14 after Painful Cervical Nerve Root Compression in the Rat. Journal of Neurotrauma, 28(12), 2429-2438. doi: 10.1089/neu.2011.1918

This is a copy of an article published in the Journal of Neurotrauma @ 2011 Mary Ann Liebert, Inc.; The Journal of Neurotrauma is available online at: http://online.liebertpub.com

This paper is posted at ScholarlyCommons. https://repository.upenn.edu/be_papers/188

For more information, please contact repository@pobox.upenn.edu. 


\title{
Schwann Cell Proliferation and Macrophage Infiltration Are Evident at Day 14 after Painful Cervical Nerve Root Compression in the Rat
}

\begin{abstract}
Although it is known that different types of nerve root insults can produce radicular pain, it is not known whether the neuronal and Schwann cell pathologies in the nerve root vary between inflammation-induced nerve root injury and traumatic compression. This study examined the extent of Wallerian degeneration and associated cellular repair processes in the nerve root in the context of mechanical hyperalgesia resulting from different modes of painful nerve root injury. The $\mathrm{C} 7$ dorsal nerve root underwent a transient 10 gram-force compression $(10 \mathrm{~g})$, inflammation-induced irritation by chromic gut exposure $(\mathrm{Cg})$, or a combination of those stimuli $(10 \mathrm{~g}+\mathrm{Cg})$. Fourteen days after injury when hyperalgesia remained, immunohistochemical analysis revealed upregulation of substance $P$, robust macrophage infiltration, myelin degeneration and debris removal, and a significant increase in the number of myelinating Schwann cells (Krox20-positive) in the compressed roots $(10 \mathrm{~g}, 10 \mathrm{~g}+\mathrm{Cg})$. $\mathrm{Cg}$ alone also produced hyperalgesia, despite being associated with intact myelin. Unilateral exposure to chromic material induced bilateral increases in macrophages and Krox20-positive Schwann cells in the nerve roots, and substance $P$ expression in the dorsal root ganglion (DRG) neurons. Results suggest that despite similar sensitivity, the extent of infiltrating macrophages and repopulated Schwann cells varies for pain from mechanical and/or chemical nerve root injury. Although these different cellular mechanisms may explain pain, they may also only reflect varying injury etiologies.

\section{Disciplines}

Biomedical Engineering and Bioengineering

\section{Comments}

Chang, Y. \& Winkelstein, B. A. (2011). Schwann Cell Proliferation and Macrophage Infiltration Are Evident at Day 14 after Painful Cervical Nerve Root Compression in the Rat. Journal of Neurotrauma, 28(12), 2429-2438. doi: 10.1089/neu.2011.1918

This is a copy of an article published in the Journal of Neurotrauma @ 2011 Mary Ann Liebert, Inc.; The Journal of Neurotrauma is available online at: http://online.liebertpub.com
\end{abstract}




\title{
Schwann Cell Proliferation and Macrophage Infiltration Are Evident at Day 14 after Painful Cervical Nerve Root Compression in the Rat
}

\author{
Yu-Wen Chang ${ }^{1}$ and Beth A. Winkelstein ${ }^{1,2}$
}

\begin{abstract}
Although it is known that different types of nerve root insults can produce radicular pain, it is not known whether the neuronal and Schwann cell pathologies in the nerve root vary between inflammation-induced nerve root injury and traumatic compression. This study examined the extent of Wallerian degeneration and associated cellular repair processes in the nerve root in the context of mechanical hyperalgesia resulting from different modes of painful nerve root injury. The $\mathrm{C} 7$ dorsal nerve root underwent a transient 10 gram-force compression $(10 \mathrm{~g})$, inflammation-induced irritation by chromic gut exposure $(\mathrm{Cg})$, or a combination of those stimuli $(10 \mathrm{~g}+\mathrm{Cg})$. Fourteen days after injury when hyperalgesia remained, immunohistochemical analysis revealed upregulation of substance $\mathrm{P}$, robust macrophage infiltration, myelin degeneration and debris removal, and a significant increase in the number of myelinating Schwann cells (Krox20-positive) in the compressed roots (10g, $10 \mathrm{~g}+\mathrm{Cg}) . \mathrm{Cg}$ alone also produced hyperalgesia, despite being associated with intact myelin. Unilateral exposure to chromic material induced bilateral increases in macrophages and Krox20-positive Schwann cells in the nerve roots, and substance P expression in the dorsal root ganglion (DRG) neurons. Results suggest that despite similar sensitivity, the extent of infiltrating macrophages and repopulated Schwann cells varies for pain from mechanical and/or chemical nerve root injury. Although these different cellular mechanisms may explain pain, they may also only reflect varying injury etiologies.
\end{abstract}

Key words: degeneration; macrophage; myelination; pain; radiculopathy; Schwann cell

\section{Introduction}

$\mathbf{R}$ ADICULOPATHY can result from a variety of disorders of the nerve root that are often caused by trauma, disc herniation, spondylosis, and stenosis (Atlas et al., 2005; Frymoyer, 1988). Although patients diagnosed with radiculopathy can experience significant neuropathic pain, the underlying mechanisms still remain unclear. Nerve root compression induces a series of pathophysiological changes in animal models including behavioral hypersensitivity, glial activation, altered neuropeptide expression, upregulation of inflammatory cytokines, and axonal and myelin degeneration (Hubbard and Winkelstein, 2005, 2008; Kawakami et al., 1994a,b; Rothman et al., 2009b; Rothman and Winkelstein, 2007; Winkelstein and DeLeo, 2004). Wallerian degeneration and the associated cellular changes that result from neural injury are essential for the processes of axonal regeneration and remyelination during healing. Radicular pain can result not only from traumatic nerve root injury that involves its compression but also from mild irritation of the nerve root (Maves et al., 1993; Rothman et al., 2009b; Rothman and Winkelstein, 2007). For example, application of chromic gut material onto the root simulating the inflammatory nucleus pulposus that can come in contact with nerve roots is sufficient to induce behavioral sensitivity, altered cytokine expression, and glial activation (Kawakami et al., 1994a,b, 1998; Maves et al., 1993; Rothman et al., 2009b; Rothman and Winkelstein 2007). Together, these studies provided strong evidence that nerve root injury-induced pain is associated with multiple cellular and biochemical modifications. However, the relationships among injured axons, activated macrophages, myelin breakdown, and repopulated Schwann cells following different types of nerve root injuries that induce behavioral changes, have not been investigated.

Nerve root injury caused by either its transient or sustained compression results in robust immune responses such as macrophage recruitment to the injury site (Gupta and Channual, 2006; Hubbard and Winkelstein, 2008; Kobayashi

Departments of ${ }^{1}$ Bioengineering and ${ }^{2}$ Neurosurgery, University of Pennsylvania, Philadelphia, Pennsylvania. 
et al., 2004a). Although macrophages perform the function of clearing debris after a tissue injury in peripheral nerves, it remains unknown whether their other actions, including promotion of demyelination during Wallerian degeneration (George et al., 2004; Kiguchi et al., 2010; Marchand et al., 2005; Martini et al., 2008), can also contribute to nerve root injuryinduced pain. Schwann cells are another glial subpopulation that participates in the pathogenesis of neuropathic pain after nerve root injury; Schwann cells also phagocytose debris, dedifferentiate, proliferate, and initiate transcription machinery (e.g., Krox20, Oct6, Sox10) for myelination in response to injury (Jessen and Mirsky, 2005; Martini et al., 2008). Although Schwann cells are essential for axonal regeneration and remyelination (Höke et al., 2006; Jessen and Mirsky, 2005), they also produce factors such as pro-inflammatory cytokines, TNF- $\alpha, \mathrm{IL}-1 \alpha, \mathrm{IL}-1 \beta$, and the trophic nerve growth factor (NGF); these factors all can influence nociceptive transmission during the process of neural repair (Campana et al., 2006; George et al., 2004; Höke et al., 2006; Shamash et al., 2002). In painful cervical radiculopathy, it remains unknown whether changes in Schwann cell function, including proliferation, dedifferentiation, and remyelination, are related to the pathogenesis of hyperalgesia.

The aim of the present study was to use existing rat models of painful cervical nerve root injury that induce mechanical hyperalgesia resulting from direct $\mathrm{C} 7$ nerve root compression and/or chromic gut suture irritation to examine the extent of neuronal and Schwann cell pathology at day 14 . Here we focused on the neuropeptide, substance $P$, because it is essential for pain signaling between the dorsal root ganglion (DRG) cells and the spinal cord dorsal horn (McLeod et al 1999; Otsuka and Yanagisawa, 1990; Weissner et al., 2006) and there is limited direct comparison of its relative involvement in mechanical and/or inflammatory insults that produce pain. In peripheral nerve injury, recruitment of macrophages is required for myelin clearance and axonal regeneration (Brown et al., 1991; Perry et al., 1987) and their secreted inflammatory mediators are highly associated with the pathogenesis of neuropathic pain (Marchand et al., 2005). To examine whether nerve root injury and/or an inflammatory insult induces similar macrophage infiltration and its associated myelin degeneration at the site of injury in the central nerve root, double-immunostaining was performed to label macrophages (using Iba1) and myelin (myelin basic protein) at 14 days after injury when Wallerian degeneration remains evident (Avellino et al., 1995; Gupta and Channual, 2006). Lastly, we examined whether remyelination and/or the myelin repair mechanism is initiated by 14 days post-injury by characterizing expression of Krox20, a transcription factor that is essential for Schwann cell remyelination (Ghislain and Charnay, 2006; Ghislain et al., 2002; Topilko et al., 1994), using immunostaining. We further probed for nestin and BrdU to determine whether Krox20-positive cells exhibited neural stem cell identity and/or the regeneration capacity.

\section{Methods}

\section{Animal groups}

All experimental procedures were performed using male Holtzman rats housed under United States Department of Agriculture and Association for Assessment and Accreditation of Laboratory Animal Care (AAALAC) approved con- ditions, with free access to food and water and a 12-h light/ dark cycle. Experiments were performed in accordance with National Research Council's guidelines for the care and use of laboratory animals and were approved by the Institutional Animal Care and Use Committee of the University of Pennsylvania. Rats, weighing 300-350 g at the time of surgery, underwent surgical procedures for nerve root compression injury using a 10 gram-force microvascular clip $(10 \mathrm{~g} ; n=8)$ or using the same clip but accompanied with chromic gut exposure to the root as well $(10 \mathrm{~g}+\mathrm{Cg} ; n=8)$. Additional groups were included for surgical controls (sham; $n=7$ ) and to control for exposure to the chromic gut only $(\mathrm{Cg} ; n=4)$. Behavioral testing was performed for 14 days following surgery to verify mechanical hyperalgesia patterns in each group and to assess hyperalgesia on the day of tissue harvest.

\section{Surgical procedures}

Surgical procedures have been described in detail previously (Hubbard and Winkelstein, 2008; Rothman et al., 2009b; Rothman and Winkelstein, 2007). Briefly, under inhalation isoflurane anesthesia ( $4 \%$ for induction, $2 \%$ for maintenance), the $\mathrm{C} 7$ dorsal root was exposed by a C6/C7 hemilaminectomy and partial facetectomy on the right side. Compression of the C7 right nerve root was performed by applying a 10 gramforce microvascular clip (World Precision Instruments, Inc; Sarasota, FL) for $15 \mathrm{~min}$ (Hubbard and Winkelstein, 2008; Rothman et al., 2009b; Rothman and Winkelstein, 2007). For the compression injury with chromic gut exposure $(10 \mathrm{~g}+\mathrm{Cg})$ 4 pieces of 3-0 chromic gut suture (Surgical Specialties; Reading, PA) were placed on nerve root after compression, as previously described (Rothman et al., 2009b; Rothman and Winkelstein, 2007). Two additional procedural groups were included to serve as controls: a sham group in which the nerve root was exposed only and a separate group in which the nerve root received chromic exposure only $(\mathrm{Cg})$, respectively (Rothman et al., 2009b; Rothman and Winkelstein, 2007). Following surgery, all wounds were closed using 3-0 polyester suture and surgical staples. Rats were recovered in room air and monitored continuously.

\section{Behavioral assessment}

Behavioral sensitivity was assessed by measuring forepaw mechanical hyperalgesia at postoperative days 1, 3, 5, 7, and 14. Each rat was evaluated for 3 days prior to surgery to provide baseline unoperated responses. A modified "updown" method developed by Chaplan was used to determine the mechanical threshold for response to stimulation (Chaplan et al., 1994; Hubbard and Winkelstein, 2005; Weisshaar et al., 2010). For each test session, rats were acclimated to the test chamber for $20 \mathrm{~min}$ prior to behavioral tests. Response thresholds were measured for each of the right (ipsilateral) and left (contralateral) forepaws by stimulating each forepaw with increasing Von Frey filament strengths (Stoelting, Wood Dale, IL), ranging from $0.6 \mathrm{~g}$ to $26.0 \mathrm{~g}$ The lowest-strength filament needed to provoke any response to five stimulations was recorded as the response threshold if the next larger filament strength also elicited a positive response. Each testing session consisted of three rounds of stimulation with the filaments of increasing strength applied to each forepaw, with at least $10 \mathrm{~min}$ between each round to allow for an adequate rest period. The thresholds determined by each round were 
separately averaged for each forepaw to obtain a single value for that forepaw for each rat on each test day.

\section{Immunohistochemistry and analysis}

The spinal cord, dorsal root, and DRG on each side at C7 were harvested en bloc at day 14 to evaluate tissue damage, local degeneration, and associated inflammatory responses in the nerve root and DRG. Rats were anesthetized and intracardially perfused with $4 \%$ paraformaldehyde in phosphate-buffered saline (PBS). Tissue samples were postfixed, cryoprotected in $30 \%$ sucrose, and embedded in OCT medium (Triangle Biomedical Sciences; Durham, NC) for cryosectioning. Six serial sections $(12 \mu \mathrm{m})$ were collected from the midline of the long axis for each nerve root onto Superfrost plus slides. Sections were blocked in $10 \%$ normal donkey serum with $0.3 \%$ Triton-X100 and incubated overnight in antibodies (guinea pig polyclonal substance P [1:500; Neuromics; Edina, MN], mouse monoclonal myelin basic protein MBP [SMI94 and SMI99 at 1:1000; Covance; Princeton, NJ] + rabbit polyclonal Iba1 [1:1000; Wako; Richmond, VA] or + rabbit polyclonal neurofilament [NF at 1:200; Sigma; St. Louis, MO], rabbit polyclonal Krox20 [1:100; Covance; Princeton, NJ]+ mouse monoclonal nestin [1:200; Invitrogen; Carlsbad, CA] or + mouse monoclonal BrdU [1: 1000; Sigma; St. Louis, MO]). Sections were washed with PBS and incubated in secondary antibodies (donkey anti-guinea pig Cy2, donkey anti-mouse Alexa 568+donkey anti-rabbit Alexa 488). After washing, sections were mounted with anti-fade gel/mount.

All sections were imaged and analyzed using a Zeiss LSM 510 confocal microscope. Expression of substance P and Iba1 was quantitated by inverting images into black (substance P) and white in the NIH Image J program to measure the percent of positive pixels in the nerve root. Substance $\mathrm{P}$ intensity (threshold scale in a 12-bit scale from 0-4098) in the DRG was measured using the histogram function of a Zeiss LSM 510 program. Krox20-positive cells were counted by a customized program developed in MATLAB software.

For the BrdU study, in a subset of rats from each group, BrdU was administered via intraperitoneal injection at a dose of $50 \mathrm{mg} / \mathrm{kg}$ (Sigma; St. Louis, MO) $2 \mathrm{~h}$ prior to perfusion and tissue harvest at day 14: sham $(n=4), 10 \mathrm{~g}(n=5), 10 \mathrm{~g}+\mathrm{Cg}$ $(n=5)$, or Cg $(n=4)$ (Rothman et al., 2009a). As with the other histological analysis for this study, six sections were acquired from the center of the root for each of these rats. Sections used for double-immunostaining of Krox20 and BrdU were denatured in $2 \mathrm{~N} \mathrm{HCl}$ for $60 \mathrm{~min}$ at $37^{\circ} \mathrm{C}$, and neutralized in $10 \mathrm{mM}$ sodium borate prior to the other customary staining procedures (Rothman et al., 2009a).

\section{Statistical analysis}

Statistical analyses were conducted using Statview (version 5.0.1, SAS; Cary, NC) with $\alpha=0.05$. Thresholds for mechanical hyperalgesia were compared using a two-way ANOVA with repeated measures to determine changes by injury group over time, followed by one-way ANOVA and Bonferroni/Dunn post-hoc correction for paired comparison among groups at each time point. For comparisons of the immunostaining outcomes (substance P, Iba1, Krox20) among nerve root injury groups, a one-way ANOVA with Bonferonni/Dunn post-hoc correction was used, with separate analyses for each of the ipsilateral and contralateral responses.

\section{Results}

Experimental nerve root injury induced immediate and sustained tactile sensitivity in the ipsilateral forepaw for all groups for up to 14 days after injury (Fig. 1). Both injuries with compression components $(10 \mathrm{~g}, 10 \mathrm{~g}+\mathrm{Cg})$ exhibited similar thresholds for eliciting a response, which was significantly lower $(p<0.004)$ than sham (Fig. 1). However, on day 7 the $10 \mathrm{~g}+\mathrm{Cg}$ group had a significantly lower $(p<0.05)$ threshold than the group with $10 \mathrm{~g}$ compression alone or with chromic exposure $(\mathrm{Cg})$ alone. Interestingly, placing chromic gut alone $(\mathrm{Cg})$ on the $\mathrm{C} 7$ nerve root was sufficient to cause chemically induced hyperalgesia in the ipsilateral forepaw on all days (Fig. 1). In contrast, although there was a reduced threshold for all groups on the contralateral paw, these differences were not significant compared to sham, except on day 7 when the $10 \mathrm{~g}+\mathrm{Cg}$ group exhibited a significantly lower threshold $(p<0.05)$ than both sham controls and the $10 \mathrm{~g}$ compression group (Fig. 1). Although by 14 days post-injury the compression groups $(\mathrm{Cg}, 10 \mathrm{~g}+\mathrm{Cg})$ also displayed contralateral mechanical hyperalgesia, the reduction in the threshold did not reach statistical significance.

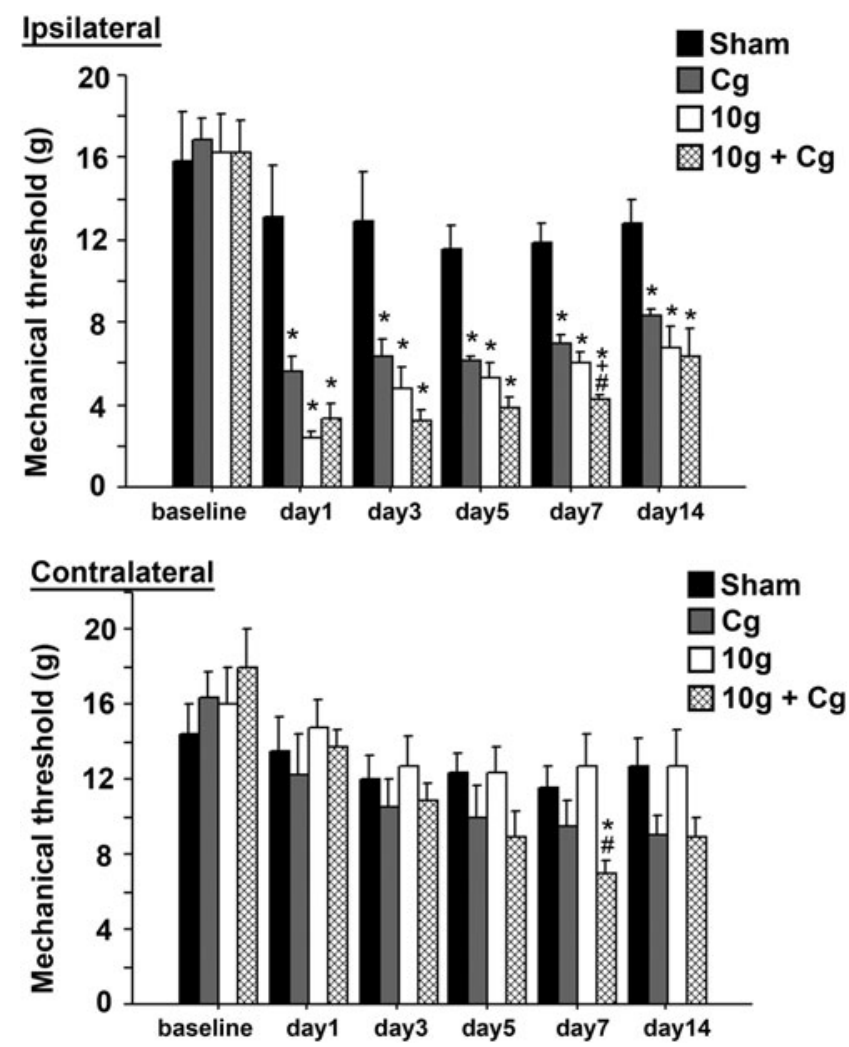

FIG. 1. Time course of response to mechanical stimulus applied to the ipsilateral and contralateral forepaws following nerve root injury. The threshold for response in the ipsilateral forepaw was significantly reduced compared to sham for all groups of nerve root injury: chromic gut exposure $(\mathrm{Cg})$, compression $(10 \mathrm{~g})$, and compression with chromic gut exposure $(10 \mathrm{~g}+\mathrm{Cg})$. Similarly, the threshold for response in the contralateral side was also decreased, with the greatest decrease in the $10 \mathrm{~g}+\mathrm{Cg}$ group. Data are plotted as mean $\pm \mathrm{SEM}$; ${ }^{*} p<0.004$ vs. sham, ${ }^{\#} p<0.05$ vs. $10 \mathrm{~g}$ and ${ }^{+} p<0.05$ vs. $\mathrm{Cg}$. 
Immunostaining revealed that substance $\mathrm{P}$ was significantly upregulated in the ipsilateral nerve root after its compression, and that the additional application of chromic to the nerve root further enhanced substance P expression (Fig. 2). There was a significant 8.5 -fold increase in the percentage of substance $\mathrm{P}$ positive area in the ipsilateral nerve root over sham $(0.35 \pm 0.10 \%)$ for the $10 \mathrm{~g}$ group $(2.99 \pm 0.79 \%, p=0.0085)$ and a 14.5-fold increase for the $10 \mathrm{~g}+\mathrm{Cg}$ group $(5.09 \pm 0.66 \%$, $p<0.0001)$ (Fig. 2B). Further, the combined injury $(10 \mathrm{~g}+\mathrm{Cg})$ also induced significantly more substance $\mathrm{P}$ expression than both the compression alone $(10 \mathrm{~g}, p=0.002)$ and the chromic exposure $(\mathrm{Cg}, 1.51 \pm 0.42 \%, p<0.0001)$ (Fig. 2B). Intense substance $\mathrm{P}$ expression was observed in small-diameter neurons in the ipsilateral DRG of all groups $(\mathrm{Cg}, 10 \mathrm{~g}, 10 \mathrm{~g}+\mathrm{Cg})$ and in small-diameter neurons in the contralateral DRG of only the groups with chromic exposure $(\mathrm{Cg}, 10 \mathrm{~g}+\mathrm{Cg})$ (Fig. 2). As measured by pixel intensity (scale $0-4098$ via LSM 510 confocal microscopy), the intensity of substance P expression in the DRG significantly increased 1.6 times in the $10 \mathrm{~g}$ group $(3102 \pm 201$, $p=0.0022), 1.82$ times in the $10 \mathrm{~g}+\mathrm{Cg}$ group $(3448 \pm 189$, $p=0.0002)$, and 1.6 times in the Cg group (3038 $\pm 167, p=0.008)$, as compared to sham responses (1896 \pm 141$)$.

On the side (left) contralateral to the injury, substance P expression was less robust but still exhibited a response in the injuries in which the right nerve root had been exposed to chromic material. For example, substance P intensity in the contralateral DRG increased 1.5 times in the $\mathrm{Cg}$ group $(2815 \pm 297, p=0.0067)$ and 1.5 times in the $10 \mathrm{~g}+\mathrm{Cg}$ group $(2978 \pm 142, p=0.0008)$ as compared to sham control (1945 \pm 65) (Fig. 2C).
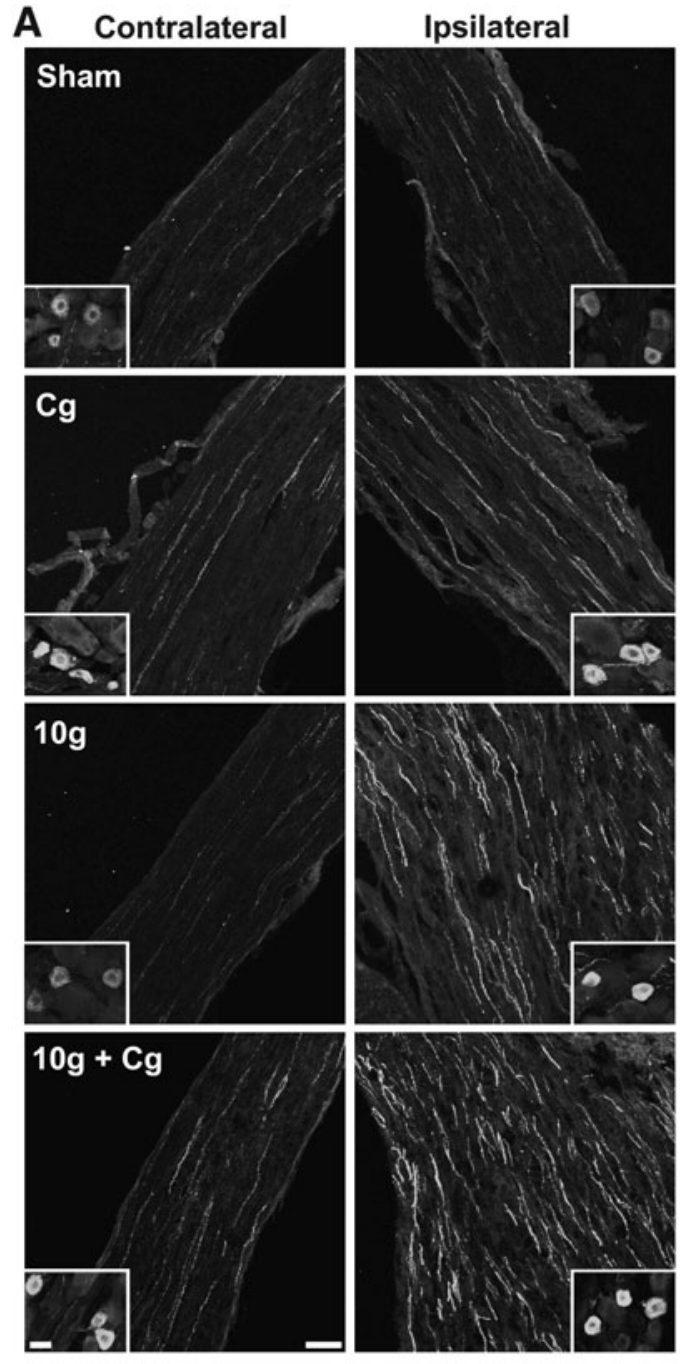

\section{B SubP+ area in nerve root}
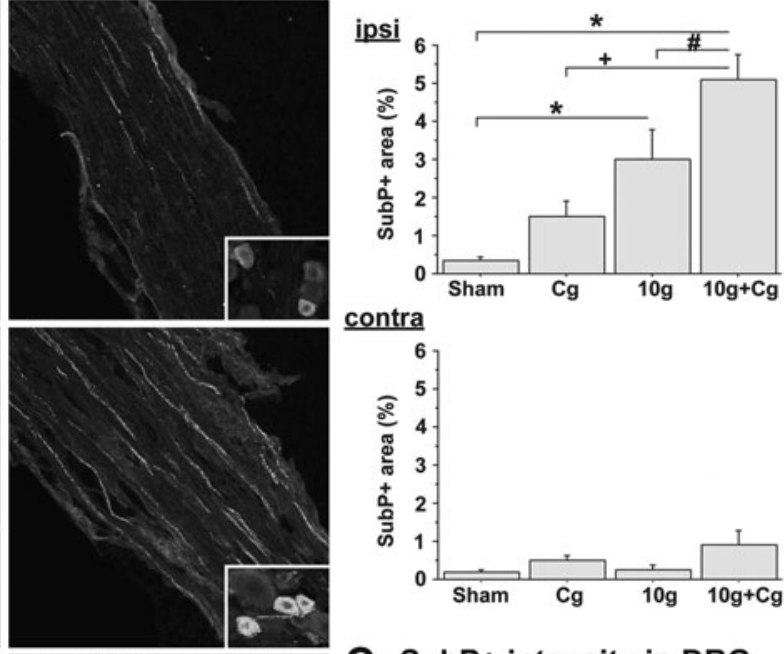

contra
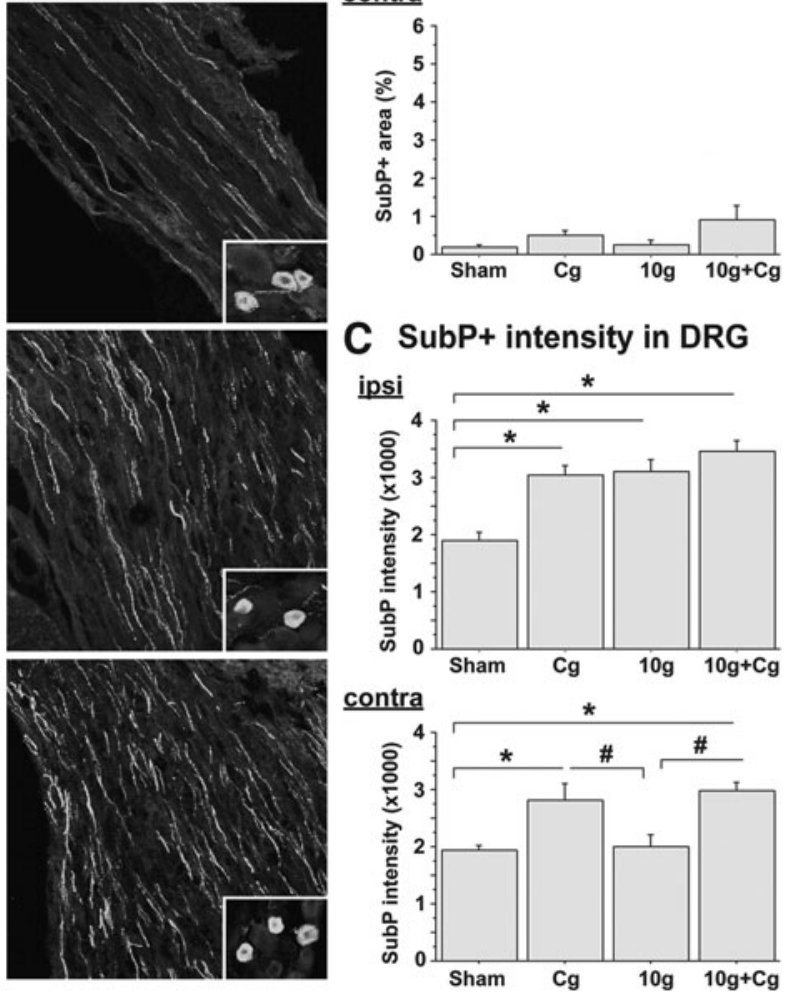

FIG. 2. Substance P expression in the nerve root and dorsal root ganglion (DRG) following nerve root injury. (A) Immunostaining of substance $\mathrm{P}(\mathrm{SubP})$ revealed increased expression in the ipsilateral nerve roots and DRG (insets) at day 14 after chromic gut exposure $(\mathrm{Cg})$, compression $(10 \mathrm{~g})$, and compression with chromic gut exposure $(10 \mathrm{~g}+\mathrm{Cg})$. Only slight and variable changes were evident in the contralateral roots and DRG. Scale bars are $50 \mu \mathrm{m}$ and apply to all panels/insets. (B) Quantification of SubP in the nerve root demonstrated significant increases in expression in the ipsilateral roots between root injuries. (C) SubP expression intensity was significantly increased in ipsilateral and contralateral DRG neurons of groups with chromic exposure $(\mathrm{Cg}, 10 \mathrm{~g}+\mathrm{Cg})$, and demonstrated a graded response in the ipsilateral DRG to injury. Data are plotted as mean \pm SEM; ${ }^{*} p<0.009$ vs. sham, ${ }^{*} p<0.003$ vs. $10 \mathrm{~g},{ }^{+} p<0.0001$ vs. $\mathrm{Cg}$. 
Although macrophage infiltration was observed after all nerve root injuries except sham, a considerable amount of macrophages was recruited to the nerve roots after the application of compression $(10 \mathrm{~g}, 10 \mathrm{~g}+\mathrm{Cg})$ (Fig. 3). The increase in Iba1-positive area in the ipsilateral nerve root was significant $(p<0.05)$ for all groups compared to sham (Fig. 3B). In addition, both compression groups exhibited significantly $(p<0.0001)$ more Iba1 staining than the Cg group (Fig. 3B). In those injury groups, macrophages exhibited a phagocytic morphology that engulfed damaged myelin and/or myelin debris (Fig. 3C). Application of chromic gut material alone did lead to macrophage recruitment in the contralateral nerve root (Fig. 3B), similar to its effect on substance P expression (Fig. 2). However, macrophages in the $\mathrm{Cg}$ group remained in their resting morphology and did not become phagocytic. MBP immunostaining revealed that the myelin sheath appeared to be intact in sham and $\mathrm{Cg}$ exposed nerve roots, whereas myelin degeneration was evident in the roots of the $10 \mathrm{~g}$ and $10 \mathrm{~g}+\mathrm{Cg}$ injury groups that included a compressive insult (Fig. 3, middle column); myelin debris and/or fragments were found consistently in the nerve root of those groups. In addition to myelin degeneration, double-immunostaining with antibodies against neurofilament (NF) and MBP to label axons and myelin revealed that NF-positive axons became noticeably thin and developed retraction bulbs in the nerve roots of groups with root compression $(10 \mathrm{~g}, 10 \mathrm{~g}+\mathrm{Cg})$ (Fig. 4). However, the NF-positive axons remained intact in sham and $\mathrm{Cg}$ groups (Fig. 4).

A

A lba1

MBP
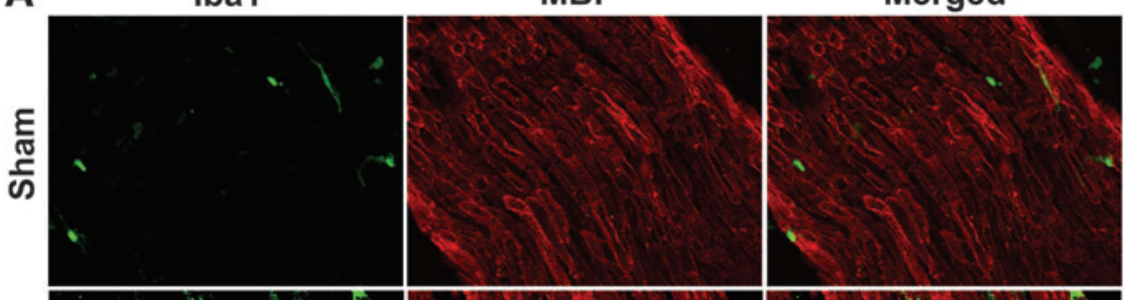

ర্
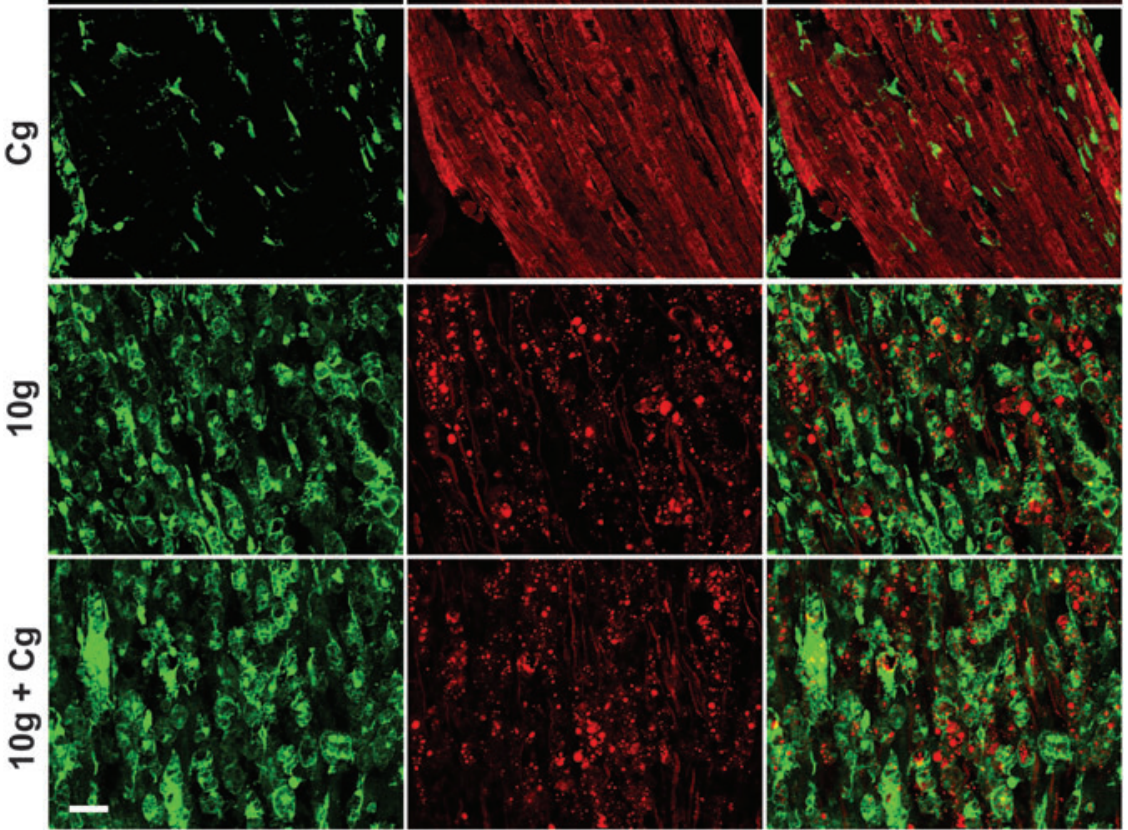

B ipsi
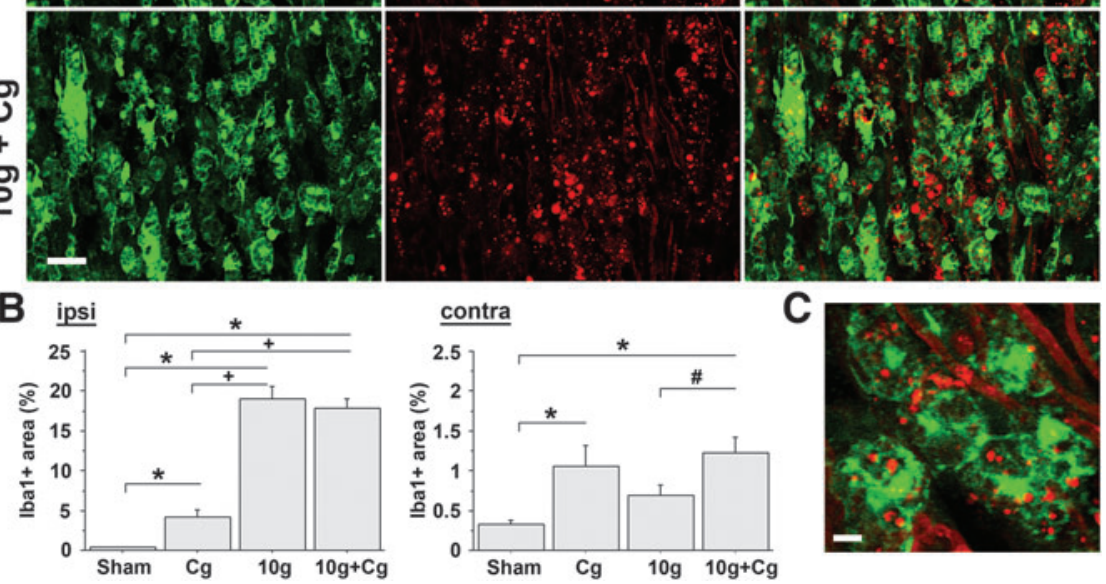

FIG. 3. Macrophage infiltration and myelin degeneration following nerve root injury. (A) Iba1 immunostaining of macrophages demonstrated infiltration after all types of nerve root injuries, with more robust responses following a compression injury $(10 \mathrm{~g}, 10 \mathrm{~g}+\mathrm{Cg}$ ). Myelin basic protein (MBP by SMI94, SMI99) immunostaining labeling myelin exhibited degeneration in both compression injury groups $(10 \mathrm{~g}, 10 \mathrm{~g}+\mathrm{Cg})$. (B) Quantification of Iba1 expression shows significant increases over sham and $\mathrm{Cg}$ after compression in the ipsilateral root. Macrophage infiltration was also evident in the contralateral nerve roots of the groups with chromic gut exposure $(\mathrm{Cg}, 10 \mathrm{~g}+\mathrm{Cg})$. (C) Higher magnification of merged image showing macrophages engulfing the myelin debris. Scale bar is $50 \mu \mathrm{m}$ in $\mathbf{A}$ and $10 \mu \mathrm{m}$ in C. Data are plotted as mean \pm SEM. ${ }^{*} p<0.05 \mathrm{vs}$. sham, ${ }^{\#} p=0.028$ vs. $10 \mathrm{~g},{ }^{+} p<0.0001$ vs. Cg. 


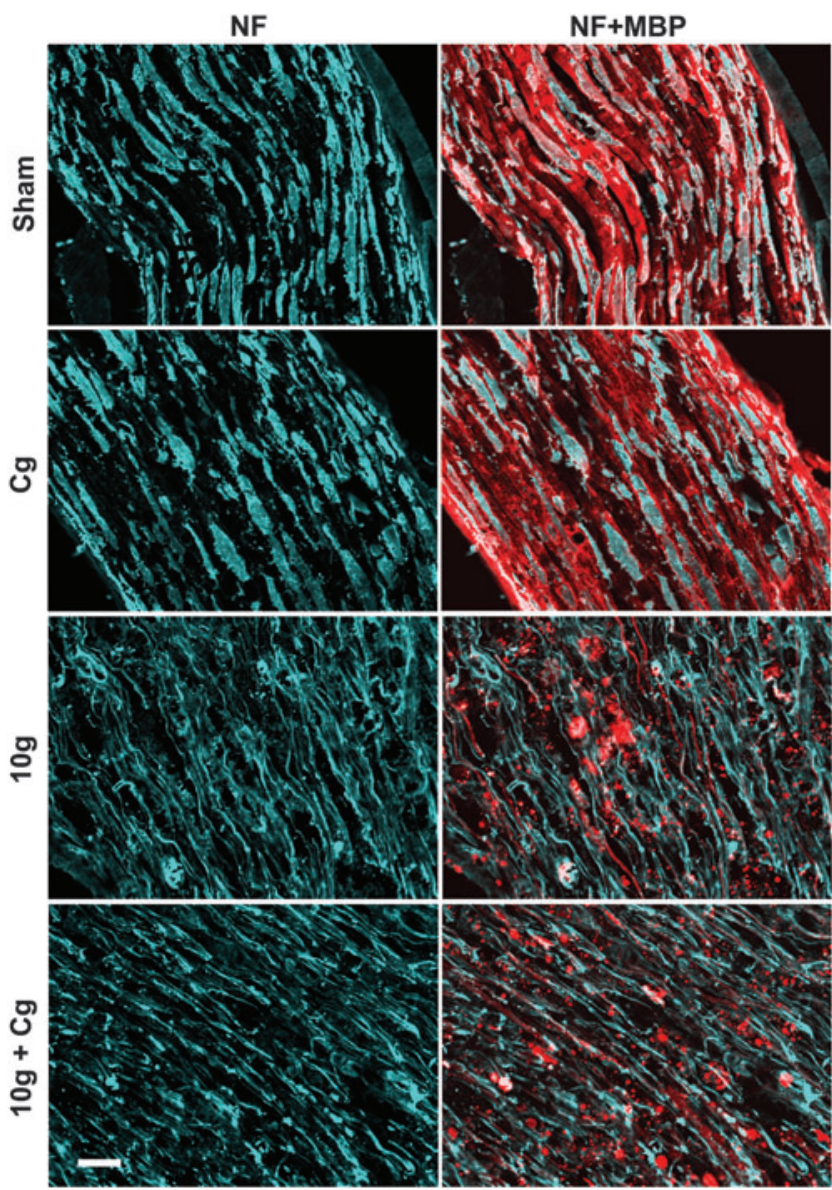

FIG. 4. Myelin degeneration is accompanied with axonal degeneration in the nerve root following compression injury. Neurofilament (NF) and myelin basic protein (MBP; by SMI94, SMI99) double immunostaining revealed damaged axons and myelin at day 14 in the groups with compression injury $(10 g, 10 g+C g)$ of the nerve root. Axon and myelin remained intact in the nerve roots after sham and Cg exposure. Scale bar is $50 \mu \mathrm{m}$ and applies to all panels.

All of the nerve root injuries were sufficient to induce Krox20 expression in the affected nerve root at day 14 (Fig. 5). However, only the injuries with a compression component induced a significant increase in Krox20 expression over sham (Fig. 5B). The density of Krox20-positive cells in the $10 \mathrm{~g}$ group $\left(239 \pm 54\right.$ cells $\left./ 450 \mu \mathrm{m}^{2}, p=0.0051\right)$ and the $10 \mathrm{~g}+\mathrm{Cg}$ group $\left(303 \pm 48\right.$ cells $\left./ 450 \mu \mathrm{m}^{2}, p=0.003\right)$ was significantly greater than that of sham controls $\left(54 \pm 9\right.$ cells $\left./ 450 \mu \mathrm{m}^{2}\right)$. The combined compression and chromic exposure group $(10 \mathrm{~g}+\mathrm{Cg})$ also exhibited significantly more Krox20-positive cells than did the Cg group (Fig. 5B). Krox20 expression was also increased in the contralateral root for those injury groups with chromic gut exposure $(\mathrm{Cg}, 10 \mathrm{~g}+\mathrm{Cg})$, with the number of Krox20-positive cells in the Cg group $\left(76 \pm 11\right.$ cells $/ 450 \mu \mathrm{m}^{2}$, $p=0.016)$ being greater than sham $\left(49 \pm 6\right.$ cells $\left./ 450 \mu \mathrm{m}^{2}\right)$ and the $10 \mathrm{~g}$ group $\left(46 \pm 3\right.$ cells $\left./ 450 \mu \mathrm{m}^{2}\right)$. The number of Krox20positive cells in the $10 \mathrm{~g}+\mathrm{Cg}$ group $\left(92 \pm 8\right.$ cells $/ 450 \mu \mathrm{m}^{2}$, $p<0.001$ ) was also significantly greater than both sham and $10 \mathrm{~g}$ (Fig. 5B). Krox20-positive cells also expressed the antibody against neural stem cell cytoskeleton protein, nestin, and displayed a bipolar shaped morphology (Fig. 5C1). The majority of Krox20-positive cells were also positive for BrdU (Fig. 5C2).

\section{Discussion}

Although the underlying mechanisms by which nerve root trauma can result in neuropathic pain are not fully understood, this study begins to characterize the integrated inflammatory and myelin degeneration responses at a time point when behavioral sensitivity persists after different types of painful nerve root trauma (Rothman et al., 2007). Compressive trauma to the nerve root induced axon and myelin destruction, together with macrophage infiltration, myelin degeneration, and proliferation of Schwann cells (Figs. 2-4). Using confocal microscopy, we show that activated macrophages exhibiting phagocytic morphology engulf myelin debris following a compressive injury $(10 \mathrm{~g})$ and also a combined compressive and inflammatory injury $(10 \mathrm{~g}+\mathrm{Cg})$ (Fig. 3). Although chemical irritation by chromic material alone $(\mathrm{Cg})$ was sufficient to lead to macrophage infiltration in the nerve root, those cells displayed a resting morphology (Fig. 3). We also demonstrate that Krox20, a key transcription factor required for Schwann cells myelination (Ghislain and Charnay, 2006; Ghislain et al., 2002; Topilko et al., 1994), is significantly increased in both the ipsilateral and contralateral nerve roots following a unilateral nerve root injury by chemical irritation alone $(\mathrm{Cg})$ or by chemical irritation combined with compression $(10 \mathrm{~g}+\mathrm{Cg})$, and that Krox20-positive cells exhibit markers for stem cells and BrdU (Fig. 5), suggesting their promyelinating activity in response to nerve root injury.

During normal nociceptive signaling, substance $\mathrm{P}$ is produced in small-diameter DRG neurons and transmitted to dorsal horn neurons through unmyelinated and thinly myelinated sensory axons in the nerve root (Willis and Coggeshall, 2004). Mechanical allodynia and hyperalgesia are induced by intrathecal delivery of substance $P$, and in transgenic mice over-expressing substance $P$, which can be reversed by antagonizing substance $\mathrm{P}$ with its receptor neurokinin 1 (NK 1) and N-methyl-D-aspartate (NMDA) (McLeod et al., 1999; Yashpal et al., 1982, 1995). In the current study, we demonstrate that transient nerve root compression, chromic gut stimulation, and their combination, induce significant increases in substance $\mathrm{P}$ expression in the nerve root at day 14 (Fig. 2), suggesting altered nociceptive transmission. Increased substance P was also evident in the C7 DRG (Fig. 2 insets). It should also be noted that unilateral application of chromic gut material alone $(\mathrm{Cg})$ is sufficient to induce bilateral upregulation of substance $P$ in the DRG, suggesting a potential diffusion effect of the inflammatory material of the chromic gut sutures and/or central sensitization. However, nerve root injury has also been reported to reduce substance $P$ when injury-induced behavioral hypersensitivity was produced (Hubbard et al., 2008a; Kobayashi et al., 2004a, 2005; Noguchi et al., 1995; Rothman et al., 2005; Xu et al., 1996). For example, we have observed decreased substance $P$ in the dorsal horn of the spinal cord and DRG at 7 days following nerve root compression dependent on the presence of mechanical allodynia (Hubbard et al., 2008a,b) and also for the same compression injury used in the current study (Rothman et al., 2005). Those decreases were observed in the spinal dorsal horn where these injured afferents synapse, and may be caused by a reduced transport to the spinal cord. The 
A Contralateral
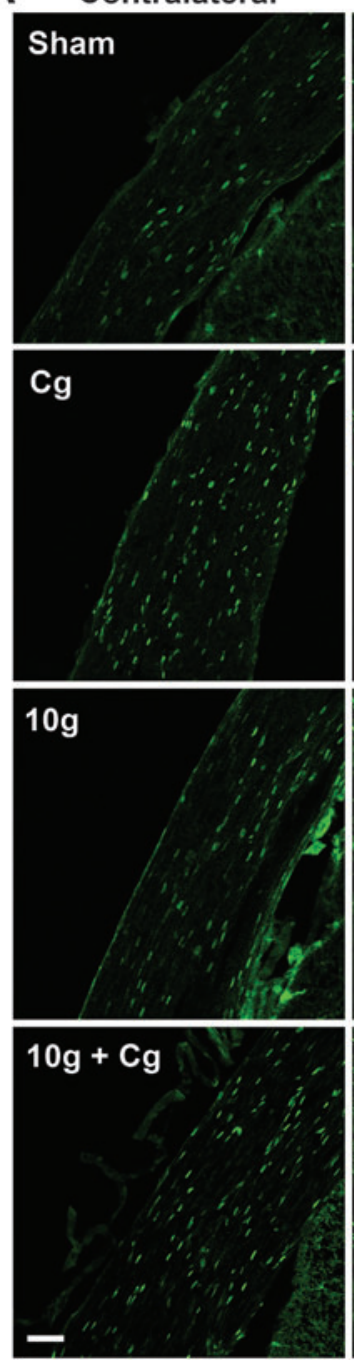

Ipsilateral
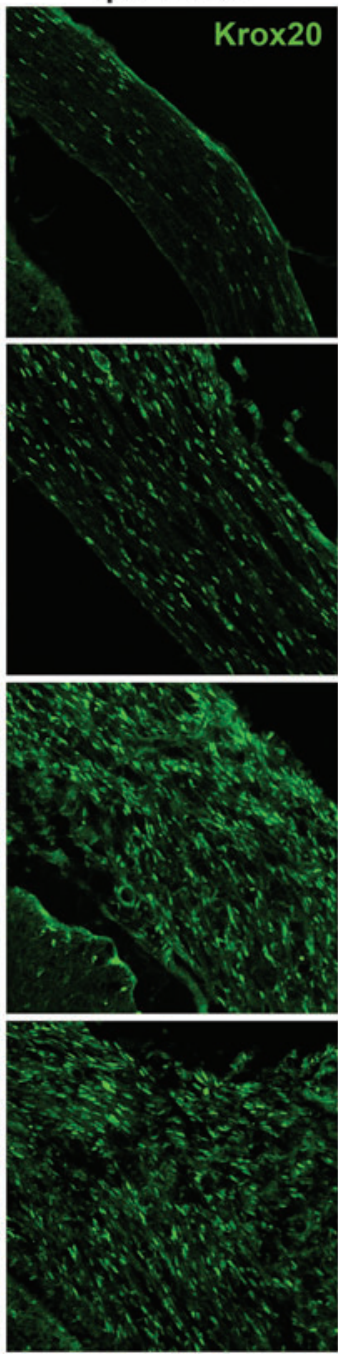

B
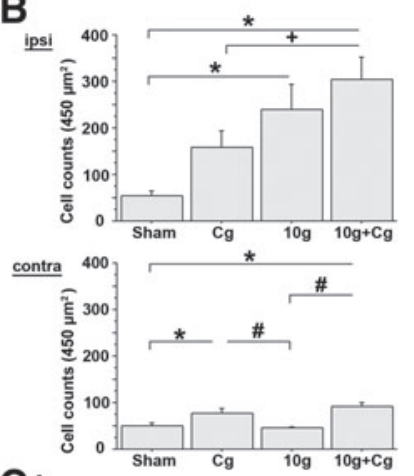

$\mathrm{C}_{1}$

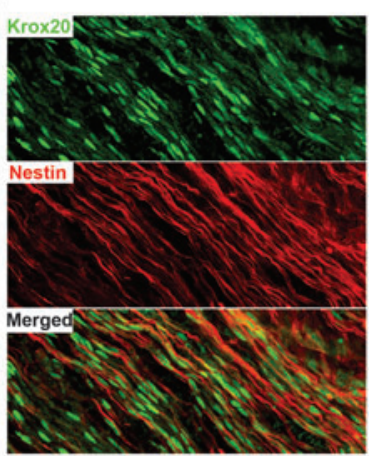

C2

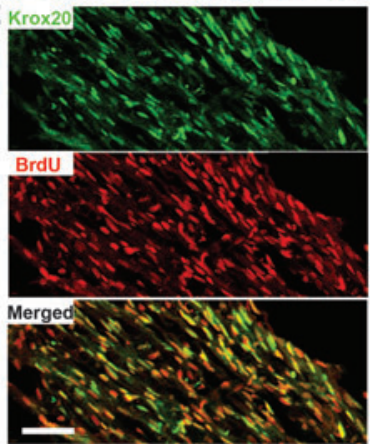

FIG. 5. Krox20 expression in the nerve root following injury. (A) Krox20 immunostaining revealed a robust increase in the ipsilateral nerve roots following injury $(\mathrm{Cg}, 10 \mathrm{~g}, 10 \mathrm{~g}+\mathrm{Cg})$ and in the contralateral nerve roots only after chromic exposure $(\mathrm{Cg}, 10 \mathrm{~g}+\mathrm{Cg})$. (B) Krox20 positive cell counts quantifying relative expression in the ipsilateral and contralateral nerve roots. (C1, C2) Double immunostaining showed that Krox20-positive cells express the neural stem cell marker, nestin, and are also positive for the proliferation marker BrdU. Scale bars in A and C2 are $50 \mu \mathrm{m}$. Data are plotted as mean \pm SEM with ${ }^{*} p<0.02$ vs. sham, ${ }^{\#} p<0.007$ vs. $10 \mathrm{~g}$, and ${ }^{+} p=0.045$ vs. $\mathrm{Cg}$.

discrepancy of substance P expression also reflects differences in the injury models and the time points examined. For example, substance P mRNA and protein levels have been reported to exhibit temporal variations in other models of pain and injury (Lee and Winkelstein, 2009). Moreover, although the immunohistochemical analysis techniques used in this study enable quantitative assessment, this and the other cellular responses could be strengthened by ELISA and/or Western blot. Nonetheless, all of these studies, including the present one, suggest that substance $\mathrm{P}$ has an important function in the pathogenesis of neuropathic pain following mechanical and/or chemical irritation to the nerve root.

It has been well documented that neural injuries result in rapid and prolonged immune responses, including immune cell infiltration, expression of inflammatory mediators and trophic factors, and induction of signaling transduction pathways, all of which contribute to the neuropathy and pain
(Marchand et al., 2005; Thacker et al., 2007; White et al., 2009). We have previously shown that macrophages are recruited to the site of injury at day 7 following different compression loads $(0-110 \mathrm{mN})$ to $\mathrm{C} 7$ nerve root (Hubbard and Winkelstein, 2008). In the present study, we directly compared macrophage responses using the same compression load (10g) with and without chromic gut exposure, and chromic gut irritation alone. Although all injury conditions induced infiltration at day 14, the most robust macrophage response was evident in the conditions with compression (Fig. 3). Interestingly, the macrophages in those two mechanical compression $(10 \mathrm{~g}$, $10 \mathrm{~g}+\mathrm{Cg}$ ) conditions displayed phagocytic morphology, whereas those in the chemical stimulation only $(\mathrm{Cg})$ condition displayed a resting morphology in the nerve root (Fig. 3A). However, unilateral chromic gut exposure, either alone or with compression, did produce a bilateral effect on macrophage infiltration as demonstrated by the increased Iba1 
immunostaining evident in both the ipsilateral and contralateral nerve roots at day 14 (Fig. 3B). These responses suggest that the inflammatory chromic gut sutures may have had widespread effects and/or induced central sensitization in the spinal cord and brain (Hunt et al., 2001; You et al., 2010). Mechanical allodynia was greatly reduced following nerve root injury in mutant Wallerian degeneration $\left(\mathrm{Wld}^{\mathrm{s}}\right)$ mice and null mice of chemokine receptor chemotactic cytokine receptor 2 (CCR2-/-), both of which display attenuated macrophage recruitment in response to injury (Abbadie et al., 2003; Sommer and Schafers, 1998). The association of macrophages with the pathogenesis of pain has also been demonstrated by a reduction in thermal hyperalgesia when circulating macrophages were depleted by clodronate administration (Liu et al., 2000). These studies, together with the current data indicating macrophage recruitment in conditions with behavioral sensitivity, support the possibility of macrophages at the injury site as mediating nerve root injury-induced pain. Accordingly, the presence of macrophages in both the resting and phagocytic forms (Fig. 2) suggests a pool of pro-inflammatory mediators that may potentiate nociception. Although the myelin sheath appears to remain intact in the condition of chromic gut alone $(\mathrm{Cg})$ (Fig. 3A) despite the presence of mechanical hyperalgesia, this behavioral response may be the result of other mediators secreted from the infiltrated macrophages.

Mechanical compression of the nerve root induced significant damage to myelin sheath (Figs. 3 and 4). Removal of myelin debris becomes essential to enable any future axonal regeneration and/or remyelination; using confocal microscopy, it is evident that most, if not all, myelin debris was completely engulfed by phagocytic macrophages by 14 days after compression injuries (Fig. 3C). Although axons appeared to be abundant and sprouting in the nerve root, they were thin and many of them developed retraction bulbs (Fig. 4) which suggest axonal dieback (Kerschensteiner et al., 2005). Compared to the intact NF-positive axons in the sham group, the abnormal morphology of the NF-positive axons in the compression groups $(10 \mathrm{~g}, 10 \mathrm{~g}+\mathrm{Cg})$ provides an additional indicator of altered nociception between the DRG and the spinal cord dorsal horn (Kobayashi et al., 2004b).

Despite the fact that remyelination was not evident in this study, we did observe significantly increased numbers of Krox20-positive cells in the nerve root after injury, which paralleled the behavioral sensitivity observed at that same time point (Figs. 1 and 5). Krox20 is an essential transcription factor expressed in myelinating lineage Schwann cells (Ghislain and Charnay 2006; Reiprich et al., 2010; Topilko et al., 1994). Mutation of Krox20 blocks Schwann cell differentiation and maturation, and myelination in the nervous system fails to occur as a result (Murphy et al., 1996; Toliko et al., 1994). Our finding of a robust increase in Krox20-positive cells after mechanical and/or chemical irritation to the nerve root suggests Schwann cells that are newly produced or preexist may have been differentiated or dedifferentiated in to a promyelinating state in preparation for remyelination when needed (Ghislain and Charnay 2006; Ghisalin et al., 2002; Topilko et al., 1994).

Schwann cells have crucial functions in providing physical and trophic support for axons. Upon axonal injury, Schwann cells execute both destructive and constructive functions, such as removal of tissue debris, proliferation, migration, release of pro-inflammatory cytokines (e.g. TNF- $\alpha$, IL-1) and trophic factors (e.g. NGF, TGF- $\beta$ ) in the process of Wallerian degeneration and regeneration (Bergsteinsdottir et al., 1991; Campana et al., 2006; Feng and Ko, 2008; Lindholm et al., 1987; Matsuoka et al., 1991; Shamash et al., 2002). The time course of these events is often accompanied by injury-induced behavioral sensitivity, which further implicates their potential role in pain. TNF- $\alpha$ and NGF are known to enhance nociception via increasing excitability of sensory neurons (Lindsay and Harmar, 1989; Sorkin et al., 1997; Urschel et al., 1991). As a source of these mediators, Schwann cells may directly or indirectly contribute to augmented nociception following nerve root injury. In the context of the literature, it is possible that the mechanical hyperalgesia observed in the present study (Fig. 1) may be caused in part by the increase in the number of myelinating Schwann cells (Krox20-positive) that produce any or all of the above-described mediators. It is also important to note that similar behavioral outcomes were observed for the different types of nerve root insults, which may also indicate that these cellular responses at the root may reflect the type of insult (inflammation alone vs. trauma). However, this study evaluated the cellular responses at the nerve root at only a single time point; therefore, it is not possible to infer temporal mechanisms or to correlate these responses with any changes in behavior or other aspects of the neuroinflammatory cascade. Additional studies are needed at other time points to fully define the relationship between Schwann cell proliferation and macrophage infiltration and activation in these models. Taken together, our demonstration of robust macrophage infiltration, myelin degeneration, and increased myelinating Schwann cells after painful nerve root compression injury suggests that the mechanical insult is associated with the adaptive processes of the injured axons, including demyelination and/or myelin removal by macrophages and repopulated Schwann cells. These findings suggest that whereas behavioral outcomes may be similar, the extent of the neuronal and Schwann cell responses may vary for different radicular pathologies and may require different therapeutic approaches to treat nerve injury-induced neuropathic pain.

\section{Acknowledgments}

This work was funded by the Catharine D. Sharpe Foundation.

\section{Author Disclosure Statement}

No competing financial interests exist.

\section{References}

Abbadie, C., Lindia, J.A., Cumiskey, A.M., Peterson, L.B., Mudgett, J.S., Bayne, E.K., DeMartino, J.A., MacIntyre, D.E., and Forrest, M.J. (2003). Impaired neuropathic pain responses in mice lacking the chemokine receptor CCR2. Proc. Natl. Acad. Sci. U.S.A. 100, 7947-7952.

Atlas, S.J., Keller, R.B., Wu, Y.A., Deyo, R.A., and Singer, D.E. (2005). Long-term outcomes of surgical and nonsurgical management of lumbar spinal stenosis: 8 to 10 year results from the maine lumbar spine study. Spine 30, 936-943.

Avellino, A.M., Hart, D., Dailey, A.T., MacKinnon, M., Ellegala, D., and Kliot, M. (1995). Differential macrophage responses in the peripheral and central nervous system during wallerian degeneration of axons. Exp. Neurol. 136, 183-198. 
Bergsteinsdottir, K., Kingston, A., Mirsky, R., and Jessen, K.R. (1991). Rat Schwann cells produce interleukin-1. J. Neuroimmunol. 34, 15-23.

Brown, M.C., Perry, V.H., Lunn, E.R., Gordon, S., and Heumann, R. (1991). Macrophage dependence of peripheral sensory nerve regeneration: possible involvement of nerve growth factor. Neuron 6, 359-370.

Campana, W.M., Li, X., Shubayev, V.I., Angert, M., Cai, K., and Myers, R.R. (2006). Erythropoietin reduces Schwann cell TNFalpha, Wallerian degeneration and pain-related behaviors after peripheral nerve injury. Eur. J. Neurosci. 23, 617-626.

Chaplan, S.R., Bach, F.W., Pogrel, J.W., Chung, J.M., and Kaysh, T.L. (1994). Quantitative assessment of tactile allodynia in the rat paw. J. Neurosci. Methods 53, 55-63.

Feng, Z., and Ko, C.P. (2008). Schwann cells promote synaptogenesis at the neuromuscular junction via transforming growth factor-beta1. J. Neurosci. 28, 9599-9609.

Frymoyer, J. W. (1988). Back pain and sciatica. N. Engl. J. Med. 318, 291-300.

George, A., Buehl, A., and Sommer C (2004). Wallerian degeneration after crush injury of rat sciatic nerve increases endoand epineurial tumor necrosis factor-alpha protein. Neurosci. Lett. 372, 215-219.

George, A., Schmidt, C., Weishaupt, A., Toyka, K.V., and Sommer, C. (1999). Serial determination of tumor necrosis factoralpha content in rat sciatic nerve after chronic constriction injury. Exp. Neurol. 160, 124-132.

Ghislain, J., and Charnay, P. (2006). Control of myelination in Schwann cells: a Krox20 cis-regulatory element integrates Oct6, Brn2 and Sox10 activities. EMBO Rep. 7, 52-58.

Ghislain, J., Desmarquet-Trin-Dinh, C., Jaegle, M., Meijer, D., Charnay, P., and Frain, M. (2002). Characterisation of cisacting sequences reveals a biphasic, axon-dependent regulation of Krox20 during Schwann cell development. Development 129, $155-166$.

Gupta, R., and Channual, J.C. (2006). Spatiotemporal pattern of macrophage recruitment after chronic nerve compression injury. J. Neurotrauma 23, 216-226.

Höke, A., Redett, R., Hameed, H., Jari, R., Zhou, C., Li, Z.B., Griffin, J.W., and Brushart, T.M. (2006). Schwann cells express motor and sensory phenotypes that regulate axon regeneration. J. Neurosci. 26, 9646-9655.

Hubbard, R.D., Chen, Z., and Winkelstein, B.A. (2008a). Transient cervical nerve root compression modulates pain: load thresholds for allodynia and sustained changes in spinal neuropeptide expression. J. Biomech. 41, 677-685.

Hubbard, R.D., Quinn, K.P., Martínez, J.J., and Winkelstein, B.A. (2008b). The role of graded nerve root compression on axonal damage, neuropeptide changes, and pain-related behaviors. Stapp Car Crash J. 52, 33-58.

Hubbard, R.D., and Winkelstein, B.A. (2005). Transient cervical nerve root compression in the rat induces bilateral forepaw allodynia and spinal glial activation: mechanical factors in painful neck injuries. Spine 30, 1924-1932.

Hubbard, R.D., and Winkelstein, B.A. (2008). Dorsal root compression produces myelinated axonal degeneration near the biomechanical thresholds for mechanical behavioral hypersensitivity. Exp. Neurol. 212, 482-489.

Hunt, J.L., Winkelstein, B.A., Rutkowski, M.D., Weinstein, J.N., and DeLeo, J.A. (2001). Repeated injury to the lumbar nerve roots produces enhanced mechanical allodynia and persistent spinal neuroinflammation. Spine 26, 2073-2079.

Jessen, K.R., and Mirsky, R. (2005). The origin and development of glial cells in peripheral nerves. Nat. Rev. Neurosci. 6, 671-682.
Kawakami, M., Tamaki, T., Hayashi, N., Hashizume, H., and Nishi, H. (1998). Possible mechanism of painful radiculopathy in lumbar disc herniation. Clin. Orthop. Relat. Res. 351, 241-251.

Kawakami, M., Weinstein, J.N., Chatani, K., Spratt, K.F., Meller, S.T., and Gebhart, G.F. (1994a). Experimental lumbar radiculopathy. Behavioral and histologic changes in a model of radicular pain after spinal nerve root irritation with chromic gut ligatures in the rat. Spine 19, 1795-1802.

Kawakami, M., Weinstein, J.N., Spratt, K.F., Chatani, K., Traub, R.J., Meller, S.T., and Gebhart, G.F. (1994b). Experimental lumbar radiculopathy. Immunohistochemical and quantitative demonstrations of pain induced by lumbar nerve root irritation of the rat. Spine 19, 1780-1794.

Kerschensteiner, M., Schwab, M.E., Lichtman, J.W., and Misgeld, T. (2005). In vivo imaging of axonal degeneration and regeneration in the injured spinal cord. Nat. Med. 11,572-577.

Kiguchi, N., Maeda, T., Kobayashi, Y., Fukazawa, Y., and Kishioka, S. (2010). Macrophage inflammatory protein-1alpha mediates the development of neuropathic pain following peripheral nerve injury through interleukin-1beta up-regulation. Pain 149, 305-315.

Kobayashi, S., Kokubo, Y., Uchida, K., Yayama, T., Takeno, K., Negoro, K., Nakajima, H., Baba, H., and Yoshizawa, H. (2005). Effect of lumbar nerve root compression on primary sensory neurons and their central branches: changes in the nociceptive neuropeptides substance P and somatostatin. Spine 30, 276282.

Kobayashi, S., Yoshizawa, H., Yamada, S. (2004a). Pathology of lumbar nerve root compression. Part 1: Intraradicular inflammatory changes induced by mechanical compression. J. Orthop. Res. 22, 170-179.

Kobayashi, S., Yoshizawa, H., and Yamada, S. (2004b). Pathology of lumbar nerve root compression. Part 2: morphological and immunohistochemical changes of dorsal root ganglion. J. Orthop. Res. 22, 180-188.

Lee, K.E., and Winkelstein, B.A. (2009). Joint distraction magnitude is associated with different behavioral outcomes and substance $\mathrm{P}$ levels for cervical facet joint loading in the rat. J. Pain 10, 436-445.

Lindholm D., Heumann, R., Meyer, M., and Thonen, H. (1987). Interleukin-1 regulates synthesis of nerve growth factor in non-neuronal cells of rat sciatic nerve. Nature 330, 658-659.

Lindsay, R.M., and Harmar, A.J. (1989). Nerve growth factor regulates expression of neuropeptide genes in adult sensory neurons. Nature 337, 362-364.

Liu, T., van Rooijen, N., and Tracey, D.J. (2000). Depletion of macrophages reduces axonal degeneration and hyperalgesia following nerve injury. Pain 86, 25-32.

Marchand, F., Perretti, M., and McMahon, S.B. (2005). Role of the immune system in chronic pain. Nat. Rev. Neurosci. 6, 521532.

Martini, R., Fischer, S., López-Vales, R., and David, S. (2008). Interactions between Schwann cells and macrophages in injury and inherited demyelinating disease. Glia 56, 1566-1577.

Matsuoka, I., Meyer, M., and Thoenen, H. (1991). Cell-typespecific regulation of nerve growth factor (NGF) synthesis in non-neuronal cells: comparison of Schwann cells with other cell types. J. Neurosci. 11, 3165-3177.

Maves, T.J., Pechman, P.S., Gebhart, G.F., and Meller, S.T. (1993). Possible chemical contribution from chromic gut sutures produces disorders of pain sensation like those seen in man. Pain 54, 57-69.

McLeod, A.L., Ritchie, J., Cuello, A.C., Julien, J.P., Ribeiro-Da-Silva, A., and Henry, J.L. (1999). Transgenic mice over-expressing 
substance $\mathrm{P}$ exhibit allodynia and hyperalgesia which are reversed by substance $\mathrm{P}$ and $\mathrm{N}$-methyl-D-aspartate receptor antagonists. Neuroscience 89, 891-899.

Murphy, P., Topilko, P., Schneider-Maunoury, S., Seitanidou, T., Baron-Van Evercooren, A., and Charnay, P. (1996). The regulation of Krox-20 expression reveals important steps in the control of peripheral glial cell development. Development 122, 2847-2857.

Noguchi, K., Kawai, Y., Fukuoka, T., Senba, E., and Miki, K. (1995). Substance P induced by peripheral nerve injury in primary afferent sensory neurons and its effect on dorsal column nucleus neurons. J. Neurosci. 15, 7633-7643.

Otsuka, M., and Yanagisawa, M. (1990). Pain and neurotransmitters. Cell. Mol. Neurobiol. 10, 293-302.

Perry, V.H., Brown, M.C., and Gordon, S. (1987). The macrophage response to central and peripheral nerve injury. A possible role for macrophages in regeneration. J. Exp. Med. $165,1218-1223$.

Reiprich, S., Kriesch, J., Schreiner, S., and Wegner, M. (2010). Activation of Krox20 gene expression by Sox10 in myelinating Schwann cells. J. Neurochem. 112, 744-754.

Rothman, S.M., Guarino, B.B., and Winkelstein, B.A. (2009a). Spinal microglial proliferation is evident in a rat model of painful disc herniation both in the presence of behavioral hypersensitivity and following minocycline treatment sufficient to attenuate allodynia. J. Neurosci. Res. 87, 2709-2717.

Rothman, S.M., Huang, Z., Lee, K.E., Weisshaar, C.L., and Winkelstein, B.A. (2009b). Cytokine mRNA expression in painful radiculopathy. J. Pain 10, 90-99.

Rothman, S.M., Hubbard, R.D., Lee, K.E., and Winkelstein, B.A. (2007). Transduction, transmission and perception of pain, in: Interventional Spine: An Algorithmic Approach. C. Slipman, F. Simeone, and R. Derby (eds), Elsevier: Amsterdam, pps. 29-37.

Rothman, S.M., Kreider, R.A., and Winkelstein, B.A. (2005). Spinal neuropeptide responses in persistent and transient pain following cervical nerve root injury. Spine 30, 2491-2496.

Rothman, S.M., and Winkelstein, B.A. (2007). Chemical and mechanical nerve root insults induce differential behavioral sensitivity and glial activation that are enhanced in combination. Brain Res. 1181, 30-43.

Shamash, S., Reichert, F., and Rotshenker, S. (2002). The cytokine network of Wallerian degeneration: tumor necrosis factoralpha, interleukin-1alpha, and interleukin-1beta. J. Neurosci. 22, 3052-3060.

Sommer, C., and Schäfers, M. (1998). Painful mononeuropathy in C57BL/Wld mice with delayed wallerian degeneration: differential effects of cytokine production and nerve regeneration on thermal and mechanical hypersensitivity. Brain Res. 784, 154-162.

Sorkin, L.S., Xiao, W.H., Wagner, R., and Myers, R.R. (1997). Tumour necrosis factor-alpha induces ectopic activity in nociceptive primary afferent fibres. Neuroscience 81, 255-262.

Thacker, M.A., Clark, A.K., Marchand, F., and McMahon, S.B. (2007). Pathophysiology of peripheral neuropathic pain: immune cells and molecules. Anesth. Analg. 105, 838-847.
Topilko, P., Schneider-Maunoury, S., Levi, G., Baron-Van Evercooren, A., Chennoufi, A.B., Seitanidou, T., Babinet, C., and Charnay, P. (1994). Krox-20 controls myelination in the peripheral nervous system. Nature 371, 796-799.

Urschel, B.A., Brown, P.N., and Hulsebosch, C.E. (1991). Differential effects on sensory nerve processes and behavioral alterations in the rat after treatment with antibodies to nerve growth factor. Exp. Neurol. 114, 44-52.

Weisshaar, C.L., Dong, L., Bowman, A.S., Perez, F.M., Guarino, B.B., Sweitzer, S.M., and Winkelstein, B.A. (2010). Metabotropic glutamate receptor-5 and protein kinase C-epsilon increase in dorsal root ganglion neurons and spinal glial activation in an adolescent rat model of painful neck injury. J. Neurotrauma 27, 2261-2271.

Weissner, W., Winterson, B.J., Stuart-Tilley, A., Devor, M., and Bove, G.M. (2006). Time course of substance P expression in dorsal root ganglia following complete spinal nerve transection. J. Comp. Neurol. 497, 78-87.

White, F.A., Feldman, P., and Miller, R.J. (2009). Chemokine signaling and the management of neuropathic pain. Mol. Interv. 9, 188-195.

Willis, W.D., and Coggeshall, R.E. (2004). Sensory Mechanisms of the Spinal Cord. Kluwer Academic/Plenum Publishers: New York.

Winkelstein, B.A., and DeLeo, J.A. (2004). Mechanical thresholds for initiation and persistence of pain following nerve root injury: mechanical and chemical contributions at injury. J. Biomech. Eng. 126, 258-263.

Xu, J., Pollock, C.H., and Kajander, K.C. (1996). Chromic gut suture reduces calcitonin-gene-related peptide and substance $P$ levels in the spinal cord following chronic constriction injury in the rat. Pain 64, 503-509.

Yashpal, K., Pitcher, G.M., Parent, A., Quirion, R., and Coderre, T.J. (1995). Noxious thermal and chemical stimulation induce increases in 3H-phorbol 12,13-dibutyrate binding in spinal cord dorsal horn as well as persistent pain and hyperalgesia, which is reduced by inhibition of protein kinase C. J. Neurosci. 15, 3263-3272.

Yasphal, K., Wright, D.M., and Henry, J.L. (1982). Substance P reduces tail-flick latency: implications for chronic pain syndromes. Pain 14, 155-167.

You, H.J., Lei, J., Sui, M.Y., Huang, L., Tan, Y.X., Tjølsen, A., and Arendt-Nielsen, L. (2010). Endogenous descending modulation: spatiotemporal effect of dynamic imbalance between descending facilitation and inhibition of nociception. J. Physiol. 588, 4177-4188.

Address correspondence to: Beth A. Winkelstein, Ph.D. Department of Bioengineering University of Pennsylvania 210 S. 33rd Street 240 Skirkanich Hall Philadelphia, PA 19104-6392

E-mail: winkelst@seas.upenn.edu 